\title{
Fault Diagnosis in Power Distribution Network Using Adaptive Neuro-Fuzzy Inference System (ANFIS)
}

\author{
Rasli $^{1}$, Hussain ${ }^{2}$ and Fauzi ${ }^{1}$ \\ 1 Universiti Teknologi Malaysia \\ 2Universiti Kebangsaan Malaysia \\ Malaysia
}

\section{Introduction}

Fault diagnosis in power distribution system is an initial action in preventing power breakdown that will affect electrical consumers. Power utilities need to take proactive plan to ensure customer satisfaction and continuous power supply. Power breakdown is a problem to utilities as well as energy users and there are a lot of factors that can cause interruption to the power system. Power distribution system is exposed to approximately $80 \%$ of overall faults that come from a wide range of phenomena including equipment failure, animals, trees, severe weather and human factors (Marusic \& GruhonjicFerhatbegovic, 2006). Whenever any of these factors befall the power system, costumers will experience power failure which will disturb their daily transactions. Since customers need smooth and reliable power supply, utilities have to develop an electrical power that has quality, reliability and continuous availability; they are responsible for the planning of power restoration properly in order to maintain high market place. Most engineers in power distribution system have decided that power breakdown is related to system reliability issues (Richard, 2009).

One problem when breakdown occurs is the long time taken to provide reenergized power after fault. To quote some examples are the power breakdown that occurred in Keningau, Sabah, East Malaysia on July 5, 2009 in which about 2 to 3 hours were taken for repairing. A power failure also happened in Lembah Klang, West Malaysia on January 13, 2005 for 5 hours that affected many industries (Fauziah, 2005). In Cameron, Middle of Africa, the engineers had taken 2 hours to detect the fault location in AES-SONEL Ngousso substation on April 2006 (Thomas \& Joseph, 2009). This phenomenon has to be considered seriously by power utilities so as to overcome frequent breakdowns and provide power restoration plan effectively. If they are unable to solve the problem effectively, they will lose consumers' confidence and power system maintenance will highly increase. In addition, power system that has low reliability encourages repeated significant faults. The faults require time for restoration. There is an index to control the duration within power interruption, which is called the customer average interruption duration index (CAIDI). Therefore, power utilities are urged to aim for low index value so that the system reliability can be maintained (Richard, 2009). 
The first step for implementing power restoration plan is by developing a precise and an accurate fault diagnosis in power distribution system. Usually, fault diagnosis involves several tasks such as fault types classification, fault location determination and power restoration plan. Firstly, the types of fault must be classified. Then, the fault location can be determined accordingly. The fault location in power distribution system is very important in order to plan power restoration through power system reconfiguration by using operational states of circuit breakers (CB) and line isolators (LI). With such plan, it can fully help power operators to make a decision immediately for further action in power restoration.

The remaining parts of the chapter are organized as follows. Section 1 explains the introduction of the chapter followed by the literature review in Section 2. In Section 3, the concept of adaptive neuro-fuzzy inference system is addressed clearly. Next the ANFIS design for fault types classification and fault location determination is described in Section 4 . The results of fault diagnosis are presented in Section 5. Finally conclusions are given in Section 6.

\section{Literature review}

Many research works on fault diagnosis incorporate artificial intelligent approaches which process the information from alarms and protection relays in power distribution and transmission systems (Zhiwei et al., 2008; Souza et al., 2004; Mohamed \& Mazumder, 1999; Binh \& Tuyen, 2006). An expert system has been implemented in cooperation with SCADA and EMS to develop a more efficient and precise centralized fault diagnosis system in transmission networks (Sekine et al., 1992). The approach registers information such as fault location, causes of fault and identifies unwanted operation of protection devices. Voltage and current sensors are installed on transmission lines for real time implementation and this involves a high cost. Artificial neural network (ANN) based fault diagnosis method in the distribution system is then developed to locate the fault, identify the faulty protection devices and isolate the faulty sections. Fault location and fault states of lines and bus sections are obtained using the information from alarm relays (Mohamed \& Mazumder, 1999). This technique provides effective information to the operator for decision making but most distribution systems are not completely equipped with alarm relays.

A combination of ANN and fuzzy logic has been used to process the information from alarms and protection relays (Souza et al., 2004) for the purpose of identifying the faulty components and line sections. A wavelet based ANN approach is developed for fault detection and classification (Silva et al., 2006). The approach uses oscillographic data from fault recorders and therefore requires communication networks between remote power system and digital fault recorders. A substation fault diagnosis system has been developed using the Petri net theory (Jingbo \& Longhua, 2006). In this method, the information from circuit breakers and faulty protection devices are configured based on mathematical formulations to calculate the precise fault section. Two Petri net concepts, namely, neural Petri net and fuzzy neural Petri net are used for locating faults at the lines or sections (Binh \& Tuyen, 2006). However, these methods are not suitable for fault diagnosis in distribution systems due to lack of information of alarm and protective relays.

A new and accurate fault location algorithm using adaptive neuro-fuzzy inference system (ANFIS) has been developed for a network with both transmission lines and under-ground 
cables (Sadeh \& Afradi, 2009). It uses fundamental frequency of three-phase current and neutral current as inputs while fault location is calculated in terms of distance in kilometer. Although it gives a good performance, there are some imperfections in the fault location due to the wide range in distance. An ANN based fault diagnosis method has been implemented in an unbalanced underground distribution system (Oliveira, 2007). The method uses fundamental voltage and current phasors as inputs to the ANN for locating faults in the line sections. Another ANN based approach which combines the ant colony optimization algorithm has been developed for fault section diagnosis in the distribution systems (Zhisheng \& Yarning, 2007). The method locates faults in terms of the line sections but the exact fault points are still not known.

\section{The concept of adaptive neuro-fuzzy inference system}

Adaptive neural fuzzy inference system (ANFIS) is based on fuzzy logic modeling and uses artificial neural network as the learning algorithm. The system can teach, change the data environment or respond to the remote stimulus for adapting to the change of data environment (Michael, 2005). ANFIS produces constant and linear target by using respective zero and first-order polynomial equations and is also known as a Sugeno-type of fuzzy inference system (FIS).

ANFIS approach targets only one output from several given inputs. The target is manipulated through the performance of the membership function curve according to a particular data input. The curve parameters are identified based on the respective weighted values via the product in between the created learning rules. A ratio between the individual and overall weighted values is calculated. The ratio is gained by using the parameters of output membership function then, finally ANFIS predicts the target by producing an overall gained value as an output. Membership function parameters in input and output sides are adjusted through a learning process to get the targeted values. ANFIS uses hybrid algorithm that consists of a combination between back-propagation and least-square estimation techniques (Jang, 1993). The techniques are implemented in artificial neural network as a learning algorithm that gives very fast convergence and more accurate in ANFIS target.

\subsection{ANFIS's learning processes}

The ANFIS model exhibits a predicted target whenever it is trained by using at least two columns of data. The last column is the target data and also as an output of the trained ANFIS, while the rest of the columns are the input data. Thus, an ANFIS structure has a single output with at least one column of input data. For the best prediction and high reliability of its performance, the model needs more elements in the column of the input data. However, this situation will also cause the processing time for learning to be slow. For that reason, the ANFIS has to be configured in a high speed processor. Every element in each row of the input data is called data variable in which the linguistic values of the relationship between them is by the rule of 'IF-THEN'. A total of the rule is proportional to the membership function value and the number of column data is linked by the following equation:

$$
\mathrm{FD}=\mathrm{P}
$$


where,

D : Total number of column for the input data

F : Number of membership functions

$P$ : Number of rules

The data is classified as training data and testing data in ANFIS's learning process. Testing data should be in the range of training data for the purpose of testing procedures. The number of training epoch also gives a good result in predicting the target. Accurate targets consider a minimum prediction error from the result of ANFIS training. The error can be reduced by adjusting the variable membership function (MF) and epoch parameters. With increasing in number of MF and epoch, the error will reduce accordingly. Sometimes, no reducing in error can be noticed even though the epoch was increased up to 5000 and above. This is due to the way the data is assembled. Therefore effective input data assembly will result good prediction. For this work, effective configuration of the data has been reached by preparing a wide data range between their elements and arranging the data from small to large values.

During the training process, MF parameters are varied so as to yield the ANFIS's output as target values. The minimum error percentage is a small difference between target and prediction values and it is used to measure the success level of a training process. ANFIS performs a hybrid learning algorithm in the training process which is a combination of two algorithms namely back-propagation and least square estimate (Jang, 1993). The hybrid method improves the bad features of individual algorithm and both are popular in ANN implementation.

In hybrid learning algorithm, MF parameters are adjusted to identify the best prediction value. The parameters determine the size of MF curve as shown in Fig.1. The curve of 'gbell' shape has been selected in the learning process due to its high performance in giving a precise prediction (Jang, 1993). There are MF curve in input and output parts of ANFIS model. Back-propagation algorithm takes responsibility to vary MF parameter in input side of the model, whereas least square estimate (LSE) takes into consideration on the output side as a linear line. In MF parameters, the input side varies, whereas for output, they are static and vice versa.

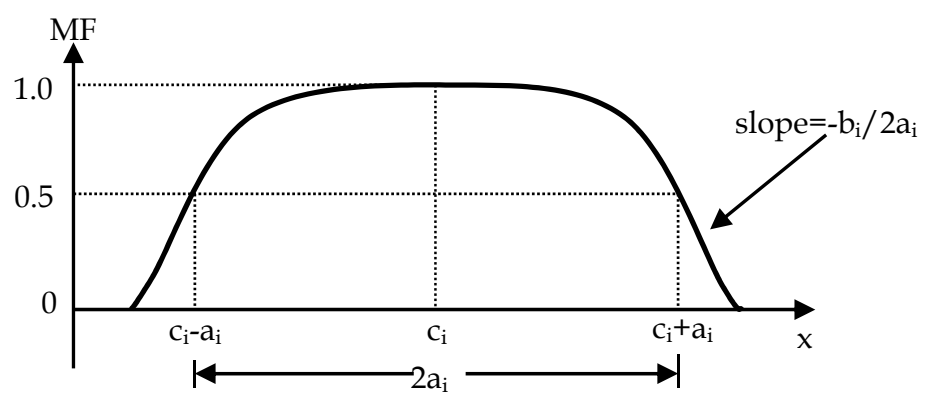

Fig. 1. Gbell shape for MF curve in input side

The prediction values are performed after the MF parameters in both sides of the ANFIS model converge the values according to the given training epoch (Mitra et al., 2008). Fig.2 
and 3 show the effect of different epoch and change of MF curve's shape with respect to the prediction error in initial and final learning process.

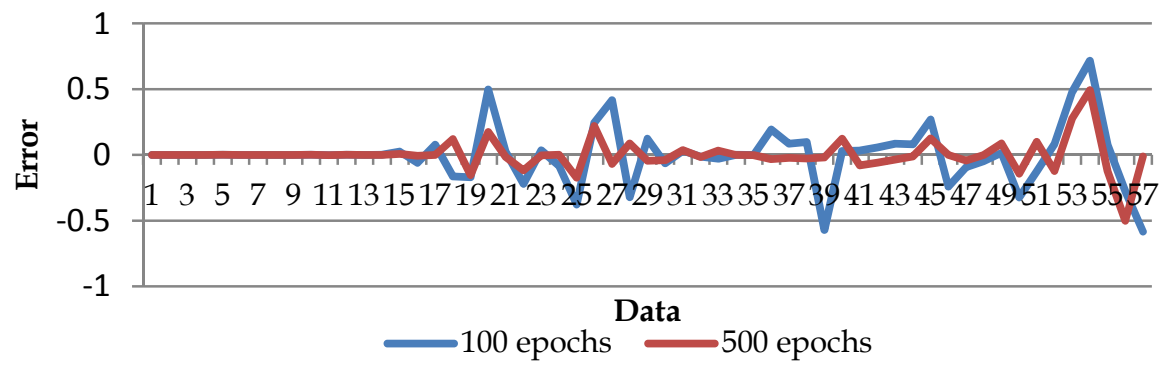

Fig. 2. Prediction errors according to different training epoch

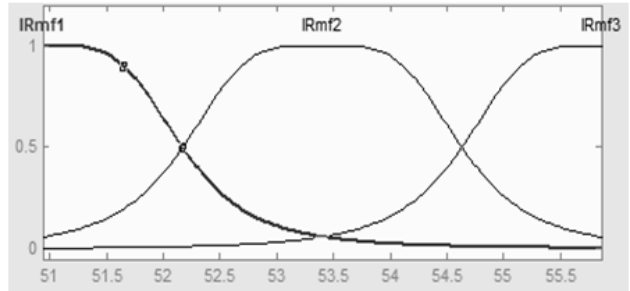

(a)

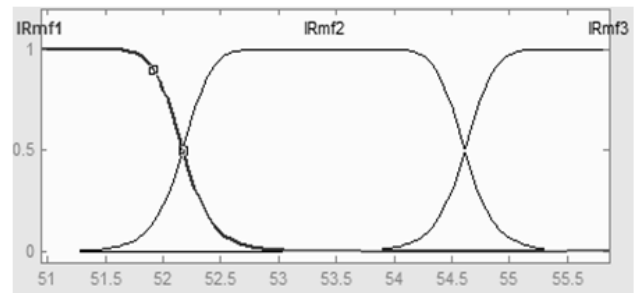

(b)

Fig. 3. (a) Initial stage and (b) MF curve of input side on final stage

ANFIS's learning process can be implemented easily by using the provided source code in Matlab such as 'newfis', 'evalfis' and editfis'. A trained ANFIS model is formatted with a file extension of '.fis' to represent an ANFIS module. On the other hand, the file is represented as a module for a particular task where all modules are configured accordingly based on a hierarchy layout to form a fault diagnosis system in power distribution network. The '.fis' file is also a flexible module that can reform when the data changes or new data is added without restructuring the model physically. ANFIS has a capability of producing very fast result in prediction even when handles a large size of input data. Therefore, the system is compliable to most application especially in adaptive control as well as ANFIS in implementing fault diagnosis. Each ANFIS module for a particular task is programmed by using source codes in Matlab. The programming is developed for every task in fault diagnosis and then the tasks are integrated in another programming to perform a simulation tool for fault diagnosis in power distribution network.

\subsection{Development of ANFIS model}

A basic ANFIS model is shown in Fig.4 in which the model is illustrated in five blocks of learning stages. This model is an example of ANFIS development model for power restoration plan that consists of two inputs and two membership functions. So, there are four fuzzy 'IF-THEN' rules to show the relationship between fault locations in ' $x, y$ ' coordinates and it also shows the operational status of CB and LI in the power distribution network. So, the target is ' 1 ' for operating while ' 0 ' for non-operating state of the devices. 
In this chapter, an ANFIS model has been developed with 27 fuzzy 'IF-THEN' rules for the task of power restoration plan as shown in Fig.5 and 8 rules in determining the fault location. Since, the number of block functions represent the rules for every input data, it is difficult to describe the operational process of the model due to lack of space. However, a basic ANFIS model is shown in Fig.4 for that purpose. There are five stages of ANFIS operational process that includes fuzzification, 'IF-THEN' rules, normalization, defuzzification and neuron addition.

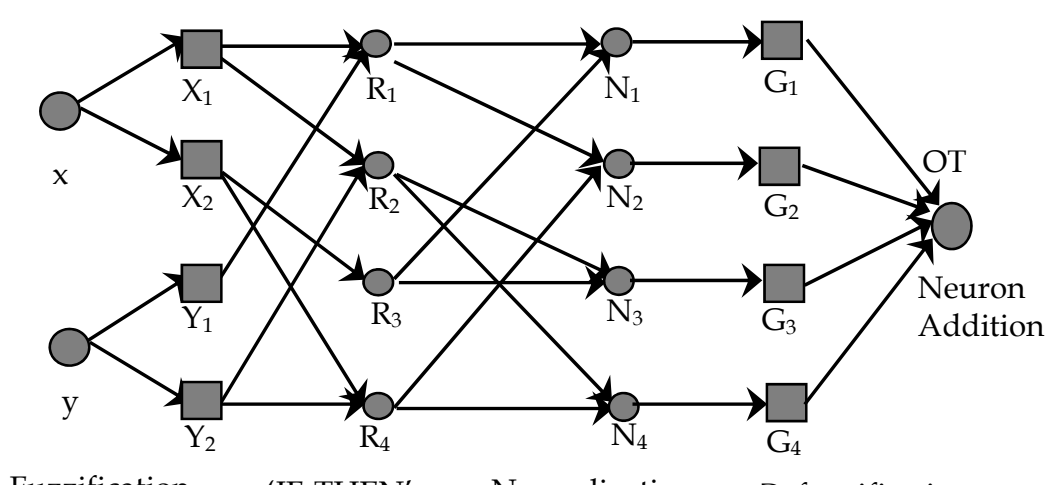

Fuzzification 'IF-THEN' Normalization Defuzzification

Fig. 4. A basic ANFIS model with two inputs data and two MFs.

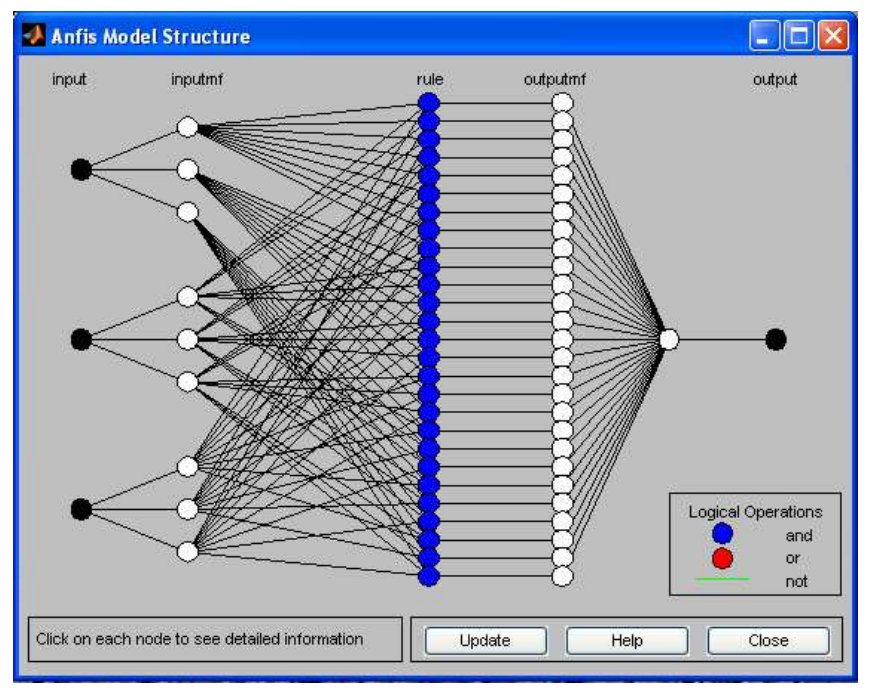

Fig. 5. An ANFIS model structure for the task of power restoration plan

\subsubsection{Fuzzification}

Referring to Fig.4, the fuzzification stage is located at the first stage of receiving of the input signal. Its function is to convert the input signal to fuzzy signal in which the signal 
is yielded via the input side of the MF curve. The curve is performed by using the following equations:

$$
\begin{aligned}
X_{\mathrm{i}}(\mathrm{x}) & =\frac{1}{1+\left(\frac{\mathrm{x}-\mathrm{c}_{\mathrm{i}}}{\mathrm{a}_{\mathrm{i}}}\right)^{2 \mathrm{~b}_{\mathrm{i}}}} \\
\mathrm{Y}_{\mathrm{i}}(\mathrm{y}) & =\frac{1}{1+\left(\frac{\mathrm{y}-\mathrm{c}_{\mathrm{i}}}{\mathrm{a}_{\mathrm{i}}}\right)^{2 b_{\mathrm{i}}}}
\end{aligned}
$$

where, $\mathrm{Xi}(\mathrm{x})$ and $\mathrm{Yi}(\mathrm{y})$ are fuzzied values for each input data, whereas $\mathrm{a}_{\mathrm{i}}, \mathrm{b}_{\mathrm{i}}$ and $\mathrm{c}_{\mathrm{i}}$ are MF parameters for respective representative of middle, width and slope of the curve as shown in Fig.1. These parameters are varied accordingly to get a suitable curve in order to get fuzzy signal.

\subsubsection{Stage of 'IF-THEN' rule}

An output signal from the fuzzification stage becomes an input to the stage of the 'IF-THEN' rule. In this stage, the fuzzy signal is gained by using equation (4) up to (7).

$$
\begin{aligned}
& R_{1}=X_{1}(x) \times Y_{1}(y) \\
& R_{2}=X_{1}(x) \times Y_{2}(y) \\
& R_{3}=X_{2}(x) \times Y_{1}(y) \\
& R_{4}=X_{2}(x) \times Y_{2}(y)
\end{aligned}
$$

$R_{1}, R_{2}, R_{3}$ and $R_{4}$ are real values for every 'IF-Then' rule.

\subsubsection{Normalization}

Next, the output signal from the stage of 'IF-THEN' rule will be an input signal to the normalization stage. In this stage, every gained signal are divided to the total of gained signal by the following equation,

$$
N_{i}=R_{i} / R_{T} \quad i=1,2,3,4
$$

where, $R_{T}=R_{1}+R_{2}+R_{3}+R_{4}$

\subsubsection{Defuzzification}

The next process is signal defuzzification in which the output signal from the normalization stage becomes an input signal to this defuzzification stage. In this stage, a normalized signal is gained again through a linear equation that is formed from the MF of the output signal as shown in the following equation,

$$
\mathrm{G}_{\mathrm{i}}=\mathrm{N}_{\mathrm{i}}\left(\mathrm{p}_{\mathrm{i}} \mathrm{x}+\mathrm{q}_{\mathrm{i}} \mathrm{y}+\mathrm{r}_{\mathrm{i}}\right) \quad \mathrm{i}=1,2,3,4
$$

with $\mathrm{p}_{\mathrm{i}}, \mathrm{q}_{\mathrm{i}}$ and $\mathrm{r}_{\mathrm{i}}$ being the MF parameters for the linear signal. 


\subsubsection{Neuron addition}

The last process in the ANFIS operation is called neuron addition in which all defuzzification signals, $\mathrm{G}_{\mathrm{i}}$ are added together as shown below:

$$
\text { OT }=\sum \mathrm{G}_{\mathrm{i}} \quad \mathrm{i}=1,2,3,4
$$

OT is a predicted value.

\subsection{Good features of the ANFIS}

The advantages of ANFIS are compared to other artificial intelligent techniques such as an artificial neural network (ANN) and an expert system (ES). The advantages are as follows; i) ANFIS gives a high precision in classification and prediction models. This precision when compared to the index error that is presented between ANFIS and ANN show the error of 0.036 and 0.32 respectively (Jang, 1993). ii) ANFIS has adaptive features to solve wrong data problem that involves new power network configuration. The scenario is rather difficult to solve using expert system due to fixed rules. iii) ANFIS has an effective learning process on the training data while considering optimization in its implementation (Jang, 1993; De Souza et al., 2003).

\section{The ANFIS design for fault types classification and fault location determination}

The development of fault diagnosis in power distribution network implements the ANFIS approach because of its compact structure, very fast training process and precise prediction. A developed fault diagnosis requires a compact ANFIS model development with significant tasks. The tasks involve fault types classification, fault location determination and identification of an operational state of CB and LI for power restoration plan. Every task is represented by an ANFIS model that is structured based on a hierarchy of power distribution network. Post-fault three-phase root mean square (RMS) current is applied to the model to produce the respective task at the output. For the purpose of developing fault diagnosis in power distribution network, such fault current is only used as the model input. If a measured current is more than the current without fault in a network, surely there is some fault in the power network. Fig.6 shows a block diagram of the fault diagnosis development that consists of four ANFIS modules. The modules are stated as ANFIS1 to ANFIS4 when representing the diagnosis tasks. From the figure, post-fault 3-phase current from the faulty power network is injected to ANFIS1 that is responsible for predicting the target in integer 1 to 10 when representing the types of fault.

Meanwhile, fault location is identified according to geometry coordinates. The same fault current as an input to the ANFIS1, is also applied to ANFIS2 and ANFIS3 modules in which they are developed to produce the output in $X$ and $Y$ coordinates respectively. In other words, the modules represent precise fault point in the power network. The technique of geometry coordinate gives better accuracy in producing the fault location compared to the cut-off faulty line approach (Butle-Pury \& Moratti 2006). Furthermore, Fig.6 shows a position of ANFIS4 module for restoration power plan in the network. The input signal to this module is from fault location identification whereas the operational states of CB and LI are the module output. The states are considered for the purpose of determination of a new power network configuration. Faulty lines must be isolated before proceeding to the power restoration plan. Binary codes are used to show the states in which digit ' 1 ' represents CB and LI in 'close' whereas digit ' 0 ' is in 'open' switch. 


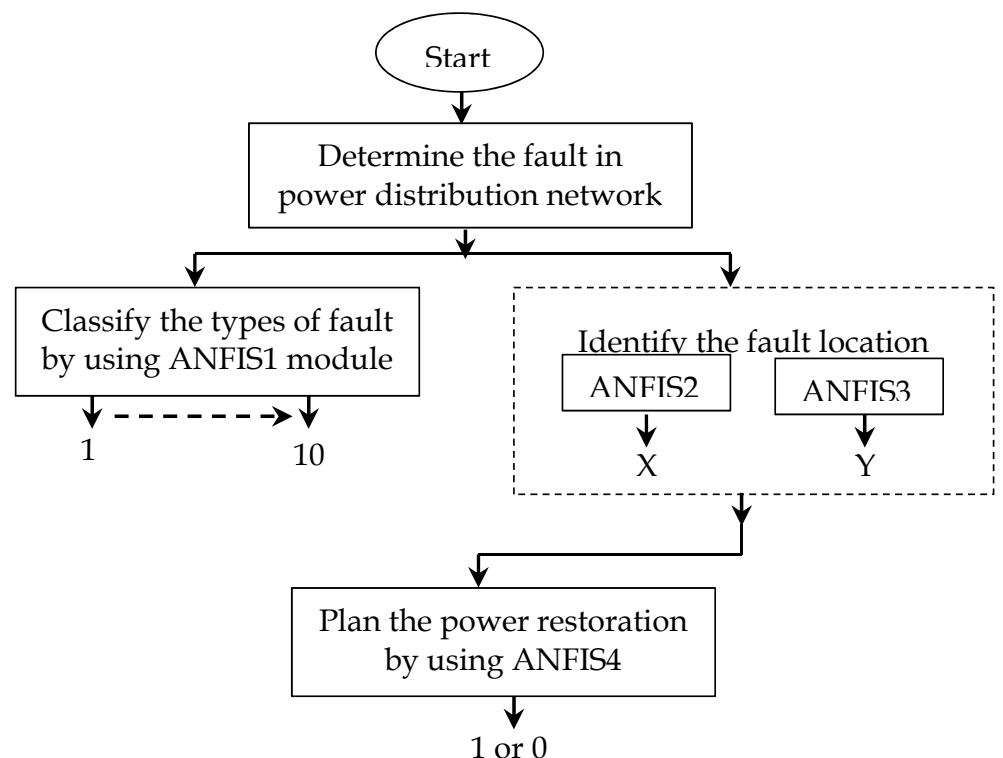

Fig. 6. A block diagram of the procedures in fault diagnosis system

\subsection{Fault types classification}

Usually, the types of power fault are classified accordingly such as a phase to ground, a phase to phase, two phases to ground and three-phase faults. Fig.7 shows ANFIS1 module

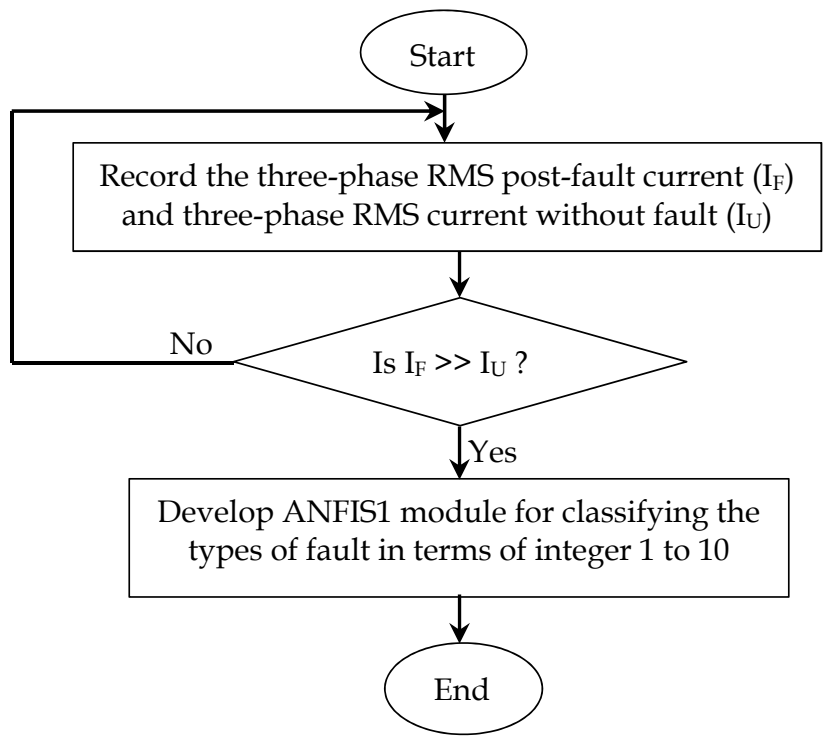

Fig. 7. A procedure in fault types classification 
development that is responsible for the task of predicting various types of fault in terms of integer 1 to 10 as follows, 1- red phase to ground fault (AG), 2 - yellow phase to ground fault (BG), 3 - blue phase to ground fault (CG), 4 - Three-phase fault (3P), 5 - red phase to yellow phase fault (AB), 6 - yellow phase to blue phase fault (BC), 7 - blue phase to red phase fault (CA), 8 - red and yellow phases to ground fault (ABG), 9 - yellow and blue phases to ground fault (BCG), 10 - blue and red phases to ground (CAG).

\subsubsection{ANFIS1 design for fault types classification}

Fig.8 shows the design of an ANFIS1 model that is structured according to the type of fault and represented by the integers 1 to 10. The model consists of ten ANFIS modules which are labeled as ANFIS1-1 to ANFIS1-10. The first module conducts A phase to ground fault (AG) prediction in integer 1 and follows by ANFIS1-2 in integer 2 for 'BG', ANFIS1-3 in integer 3 for ' $C G$ ' and so on. ANFIS1-4 to ANFIS1-10 modules represent respective 3P, AB, BC, $C A$, ABG, BCG and CAG faults. Table 1 shows some relationship parameters between the input and output of ANFIS1's signals.

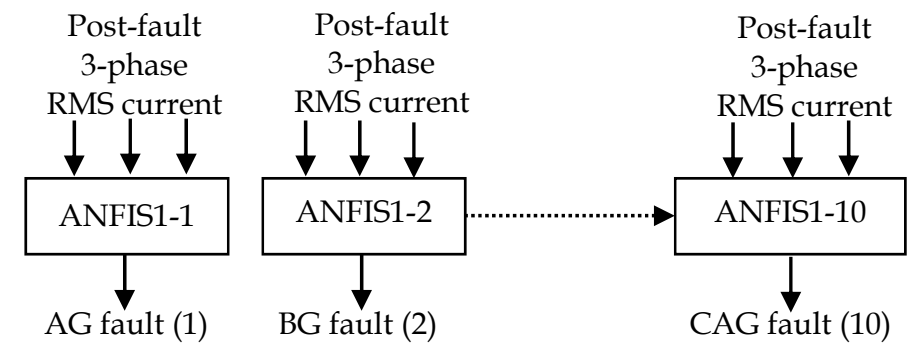

Fig. 8. ANFIS1 design for fault types classification

\begin{tabular}{|c|c|c|}
\hline ANFIS modules & Input & Output \\
\hline ANFIS1-1 & Post-fault 3-phase RMS current & $1-$ AG fault \\
\hline ANFIS1-2 & " & $2-$ BG fault \\
\hline ANFIS1-3 & " & 3 - CG fault \\
\hline ANFIS1-4 & " & $4-3$ P fault \\
\hline ANFIS1-5 & " & 5 - AB fault \\
\hline ANFIS1-6 & " & $6-$ BC fault \\
\hline ANFIS1-7 & “ & 7 - CA fault \\
\hline ANFIS1-8 & " & $8-\mathrm{ABG}$ fault \\
\hline ANFIS1-9 & “ & 9- BCG fault \\
\hline ANFIS1-10 & $"$ & 10 - CAG fault \\
\hline
\end{tabular}

Table 1. Input and output parameters from every ANFIS1 module.

\subsubsection{A Procedure for classifying the types of fault}

Fig.9 shows a procedure for classifying various types of fault in power distribution network through developing an ANFIS1 model. The first step is the preparation of power network in 
$\mathrm{XY}$ coordinate layout. The selected power distribution network is a 47 buses practical system. Then, by using the commercial software of PSS-ADEPT, the network is analyzed to record a post-fault 3-phase RMS current for each identified fault point. These points are fault location in $\mathrm{XY}$ coordinates for every feeder and radial lines including loads. The post-fault current data is used to train ANFIS1-1 to ANFIS1-10 modules according to respective target output that are integers 1 up to 10. The integers are representative of 10 types of fault. There are 163 selected coordinates for fault points with two fault resistors in the 47 buses practical power network. Therefore, it has about 2462 simulations in generating the data set. Table 2 shows a distribution data for training, testing and classifying the types of fault in the practical system.

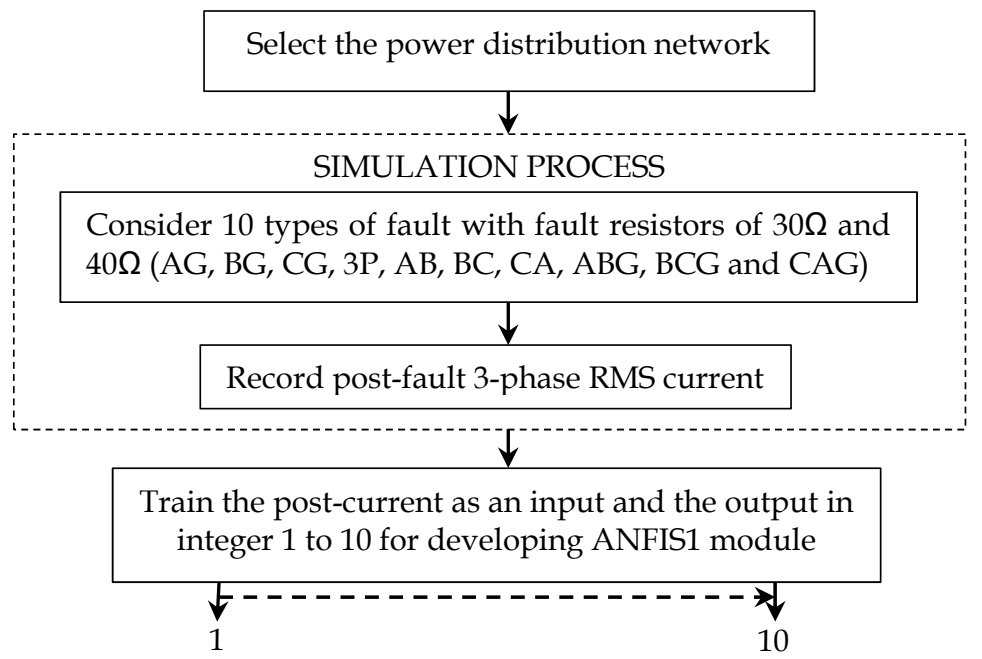

Fig. 9. A procedure for developing ANFIS1 in fault types classification

\begin{tabular}{|c|c|c|c|c|}
\hline ANFIS1 module & $\begin{array}{c}\text { Generated } \\
\text { data set }\end{array}$ & $\begin{array}{c}\text { Trained } \\
\text { data set }\end{array}$ & $\begin{array}{c}\text { Number of } \\
\text { ANFIS } \\
\text { input }\end{array}$ & $\begin{array}{c}\text { Number of } \\
\text { ANFIS } \\
\text { output }\end{array}$ \\
\hline ANFIS1-1 to ANFIS1-3 & 465 & 445 & 3 & 1 \\
\hline ANFIS1-4 & 177 & 157 & 3 & 1 \\
\hline ANFIS1-5 to ANFIS1-10 & 182 & 162 & 3 & 1 \\
\hline
\end{tabular}

Table 2. The training and testing data for classifying the types of fault in a 47 buses practical system

\subsection{Fault location identification}

Referring to Fig.10, ANFIS2 and ANFIS3 are developed to identify fault location in respective $X$ and $Y$ coordinates. According to previous literature, most of the methods in identifying the fault location for power distribution network are in fault distance from a substation or zone. This approach considers geometrical coordinates in determining fault location in which it produces more accurate and precise fault location identification. From 
Fig.10, three-phase RMS post-fault current with $\left(\mathrm{I}_{\mathrm{F}}\right)$ and without $\left(\mathrm{I}_{\mathrm{U}}\right)$ fault are compared to investigate the fault in the power system. If current is $I_{F}$ higher than current $I_{U}$, the current $I_{F}$ is recorded with the merging fault type.

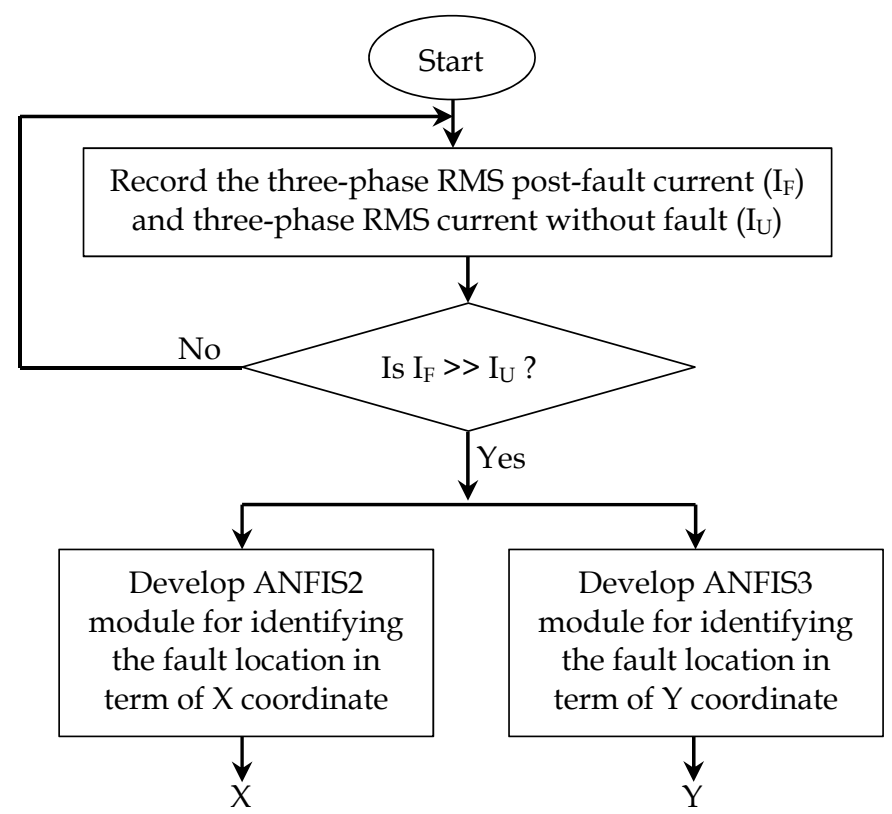

Fig. 10. A procedure for identifying fault location

\subsubsection{ANFIS2 and ANFIS3 designs for identifying fault location}

The structure of ANFIS2 and ANFIS3 are configured according to selected fault points as shown in Fig.11. For a 47 buses practical system, there are 163 fixed fault points with 64 ' $X$ ' coordinates and $45^{\prime} \mathrm{Y}^{\prime}$ c coordinates. Thus, the total coordinate point is 109 . Those points are
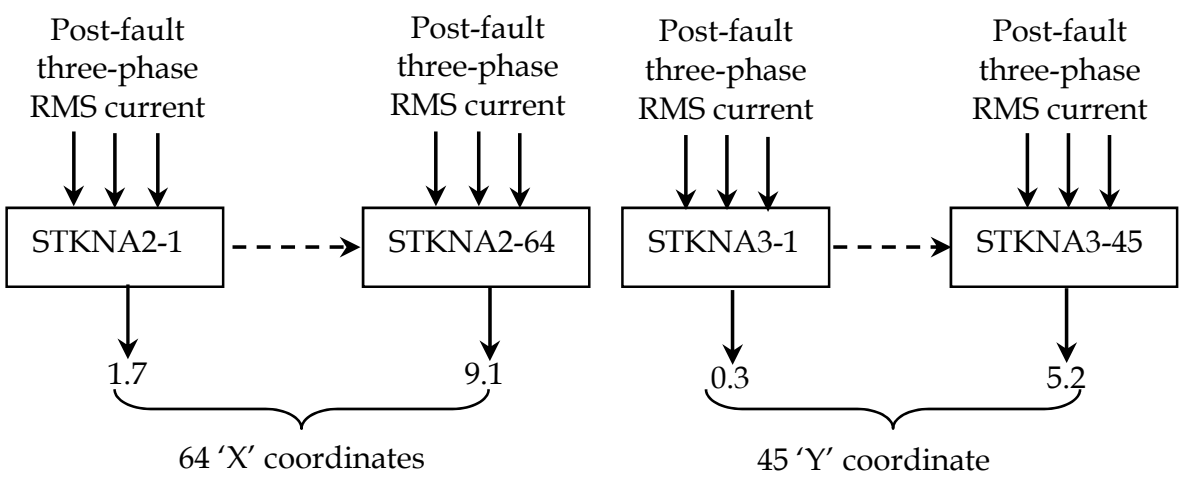

Fig. 11. ANFIS2 and ANFIS3 design for identifying fault location in a 47 buses practical system 
represented by each ANFIS module. ANFIS2 consists of 64 modules that are labeled as ANFIS2-1 up to ANFIS2-64 whereas for ANFIS3, its total module is 45 from ANFIS3-1 to ANFIS3-45. The signal input to the ANFIS2 and ANFIS3 is a three-phase RMS post-fault current while the signal output is in terms of $X$ and $Y$ coordinates respectively as shown in Fig.11. Table 3 shows the input and output parameters of the 47 buses practical system.

\begin{tabular}{|c|c|c|}
\hline ANFIS module & Input & Output \\
\hline ANFIS2-1 & Post-fault 3-phase RMS current & 1.7 \\
\hline $\begin{array}{l}1 \\
1 \\
\downarrow\end{array}$ & & $\begin{array}{l}\mathbf{1} \\
\mathbf{1} \\
\downarrow\end{array}$ \\
\hline ANFIS2-64 & “ & 9.1 \\
\hline ANFIS3-1 & “ & 0.3 \\
\hline $\begin{array}{l}1 \\
1 \\
v\end{array}$ & & $\begin{array}{l}\mathbf{1} \\
\mathbf{y}\end{array}$ \\
\hline ANFIS3-45 & " & 5.2 \\
\hline
\end{tabular}

Table 3. Input and output parameters of ANFIS2 and ANFIS3 for identifying fault location in a 47 buses practical system

\subsubsection{A procedure for identifying fault location}

The procedure for locating fault in a power distribution network by the implementation of ANFIS2 and ANFIS3 modules is clearly shown in Fig.12. The first stage is a selection of power network for testing. Then the network layout is drawn in $\mathrm{XY}$ plane for locating the selected fault points along the feeder and radial lines. Fig.13 presents an example of the layout. The detail specification of the network is in the next sub-section. This network layout is embedded in fault analysis simulation software such as PSS-ADEPT to collect the fault current data at each fault point.

Next, the three-phase RMS post-fault current is collected at the main substation through a simulation of fault analysis to the selected power distribution network. The fault analysis is applied to every point of the fixed coordinates while considering 10 types of fault and several fault resistors $\left(\mathrm{R}_{\mathrm{f}}\right)$. For example, by using three fault resistors and 163 fault points, there are 1335 simulations for single fault to ground and about 486 simulations for double fault to ground. Meanwhile, about 643 simulations are required for phase to phase and three-phase faults. Therefore, the total simulation is about 2464 for power distribution network in the 47 buses practical system. The data collected is arranged in such a way that it has three columns of input parameters and one column of target values. The target is either $\mathrm{X}$ or $\mathrm{Y}$ coordinates in which they are used to train ANFIS2 and ANFIS3 respectively. 
By identifying the fault location in terms of ' $X Y^{\prime}$ ' coordinates, more precise and accurate location not only in terms of distance from the feeding substation can be yielded. The structure of ANFIS2 and ANFIS3 are quite simple so they undergo a very fast process in the training stage. However, the simulation process should be done repeatedly due to too much fixed fault points in selected power distribution network. If any network has more feeder and radial lines with long line distance, the fault point should also be more. Thus, the number of ANFIS models will also increase.

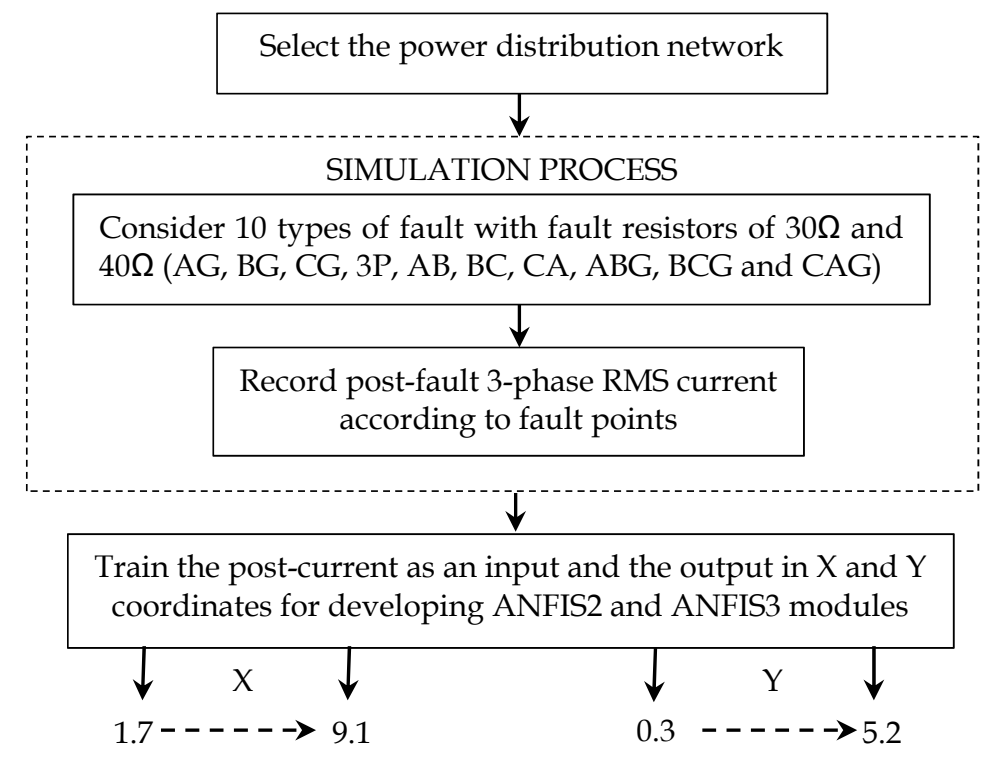

Fig. 12. A procedure for developing ANFIS2 and ANFIS3 in fault location identification

\subsubsection{The 47 buses practical system}

A single line diagram of the 47 buses practical system is illustrated in Fig.13. The system has seven $11 \mathrm{kV}$ feeders and four $33 \mathrm{kV}$ feeders including $87 \mathrm{CBs}$ and 9 LIs in $11 \mathrm{kV}$ feeder. In this chapter, only $11 \mathrm{kV}$ feeders are used for simulating and testing in order to observe the performance of the developed fault diagnosis system. There are about 2464 line data of three-phase RMS post-fault current that is recorded during the simulation stages. Bus B1 is a power source bus in which it is located on coordinate $(1,2.2)$ while a monitoring bus B2 is coordinated on $(1.8,2.7)$. B2 is used for recording the three-phase RMS post-fault current during fault. 


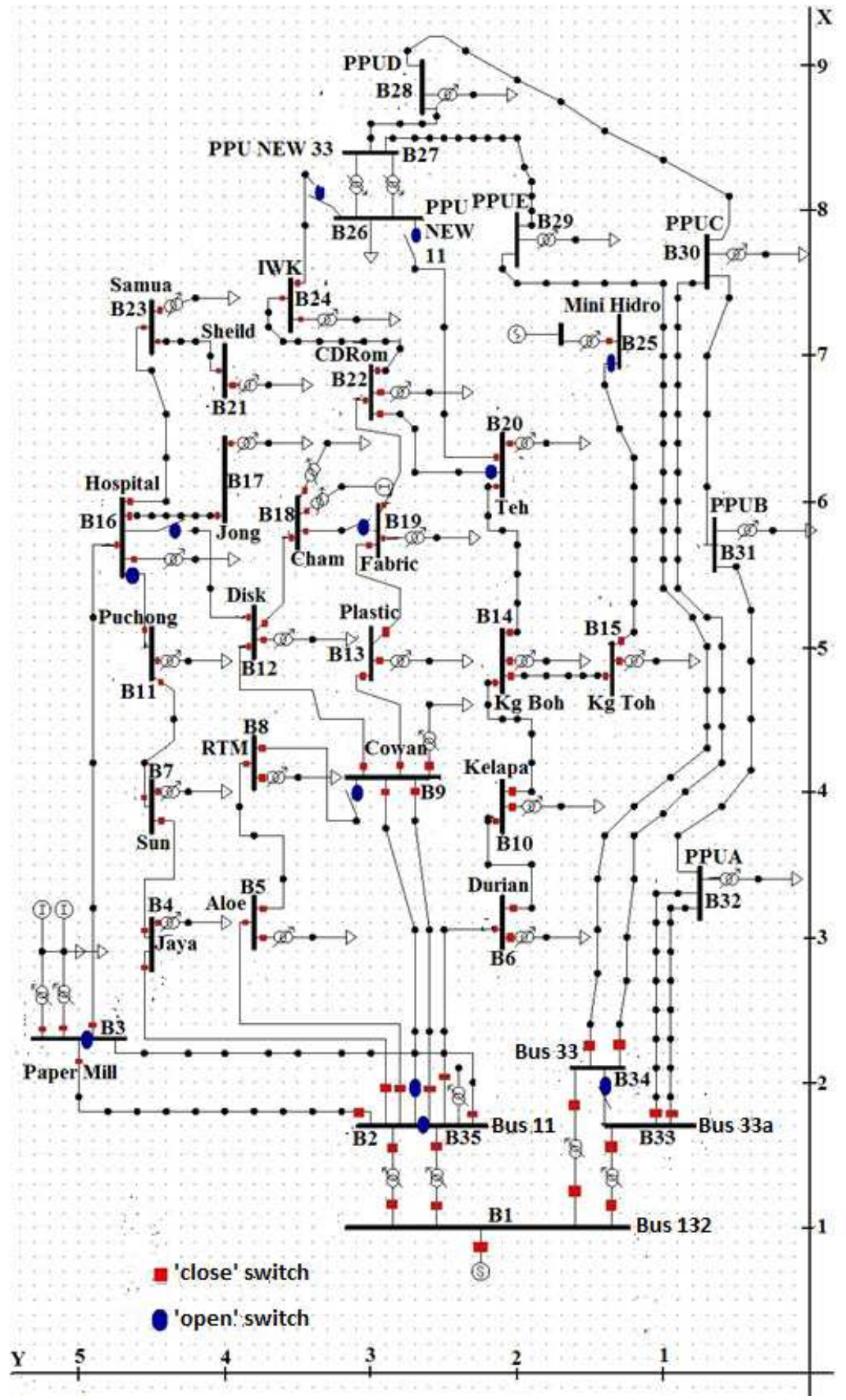

Fig. 13. A single line diagram of 47 buses practical system 


\subsection{Power restoration plan}

Power restoration is a very important consideration in the development of fault diagnosis system especially in a distribution network. Hence, easy and fast action must be taken seriously to plan a power restoration procedure so that the power can be reenergized immediately in a safe and proper manner. This problem can be solved using the ANFIS approach by applying the operational states of CB and LI as shown in Fig.14. This simple technique uses only fault points in $X Y$ coordinates and the target is in operational states of CB and LI. These parameters are trained to develop the ANFIS4 model. The power restoration plan considers some requisite processes before developing the ANFIS4 module which are as follows: make sure the power network has a support feeder or a radial that is the nearest to fault feeders. No service loads due to line isolation (NSL) must be calculated in volt-ampere (VA). In addition, the total of loads in the supported feeder (TSL) and actual capacity of the feeder (CSF) should be defined clearly. If NSL is smaller than the differentiation between CSF and TSL, the power restoration plan will be carried to the next action.

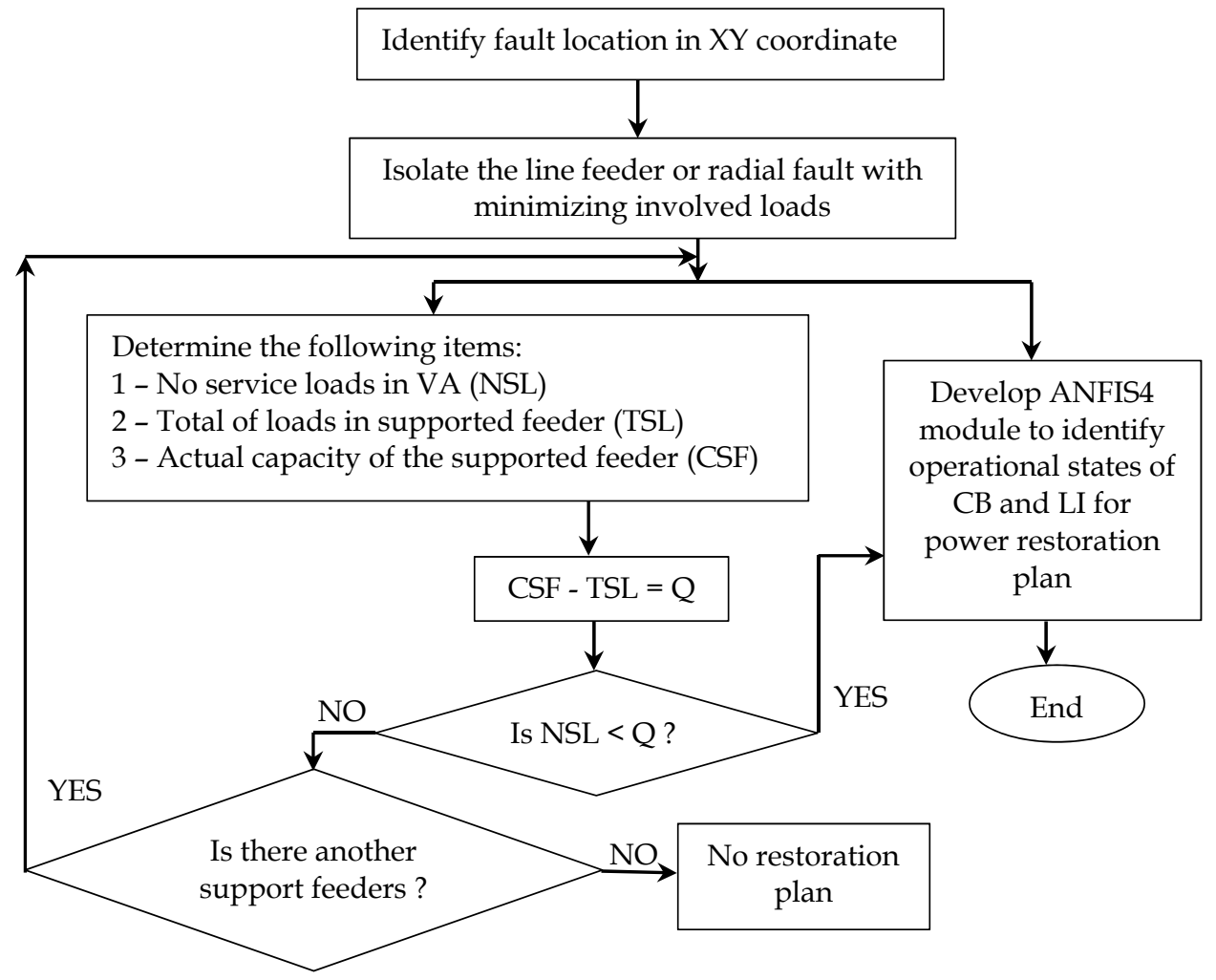

Fig. 14. A procedure for planning power restoration 


\subsubsection{ANFIS4 design for planning power restoration}

Fig.15 shows an ANFIS4 design in a power restoration plan in a 47 buses practical system. The design has 93 modules namely ANFIS4-1 to ANFIS4-93 according to the total of CB and LI in the power network. The input and output data to the ANFIS4 are XY coordinates and binary number respectively. The binary represents the operational states of CB and LI as listed in Table 4. Digit ' 1 ' indicates 'close' position while ' 0 ' is for 'open' position.

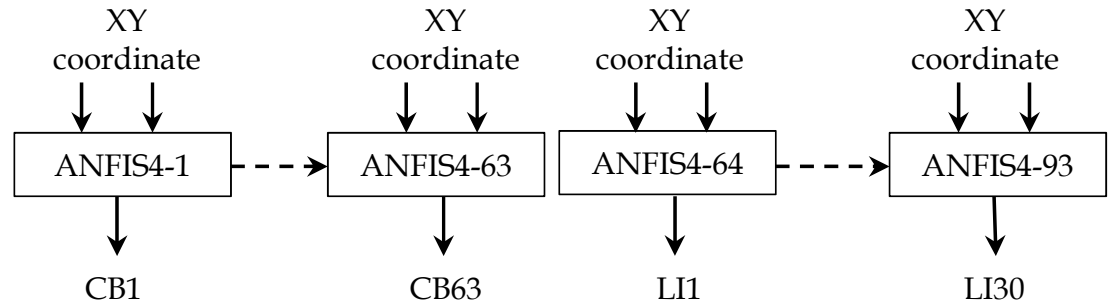

Fig. 15. ANFIS4 design for power restoration plan

\begin{tabular}{|c|c|c|}
\hline ANFIS module & Input & Output \\
\hline ANFIS4-1 & Post-fault 3-phase RMS current & 1 or 0 \\
\hline 1 & & 1 \\
$\downarrow$ & & $\downarrow$ \\
\hline ANFIS4-93 & “ & 1 or 0 \\
\hline
\end{tabular}

Table 4. Input and output parameters for ANFIS4 module in power restoration plan

\subsubsection{A procedure to train ANFIS4 for power restoration plan}

There are several steps in developing ANFIS4 as well as collecting and training the data for the purpose of power restoration plan. The steps are as follows:

i. Isolate the fault feeder or radial with the minimized load.

ii. Identify the non-service loads (NSL) in volt-ampere (VA).

iii. Identify support feeder or radial that is available to the fault feeder and determine its load total (TSL).

iv. Identify the support feeder capacity (CSF) in the power distribution network.

v. Calculate the difference between CSF and TSL.

vi. If NSL is greater than the difference, identify another support feeder or radial. If the feeder is available, repeat steps (iii) to (vi). But if the feeder is not available, the power restoration plan cannot proceed.

vii. If the NSL is smaller than the difference, the plan shall be implemented with a procedure as shown in Fig.16.

In this case, a 47 buses practical system has been selected for developing and testing the ANFIS4 module. There are 59 fixed fault points in the selected network, so the collected 
data has about 5487 lines which includes $63 \mathrm{CBs}$ and 30 LIs in the practical system. Each line consists of three rows including $X, Y$ coordinates and the integer ' 1 ' or ' 0 ' represents an operational state of $\mathrm{CB}$ and LI. The point coordinates are the input signal to the ANFIS4 whereas the integer is the output. Due to the 93 devices for all CBs and LIs, the ANFIS4 modules should be developed regarding to the numbers of the device. Thus, the modules are labeled as ANFIS4-1 to ANFIS4-63 for all CBs and followed by ANFIS4-64 to ANFIS4-93 for all LIs. Table 5 shows a distribution of the data set for each module to train them.

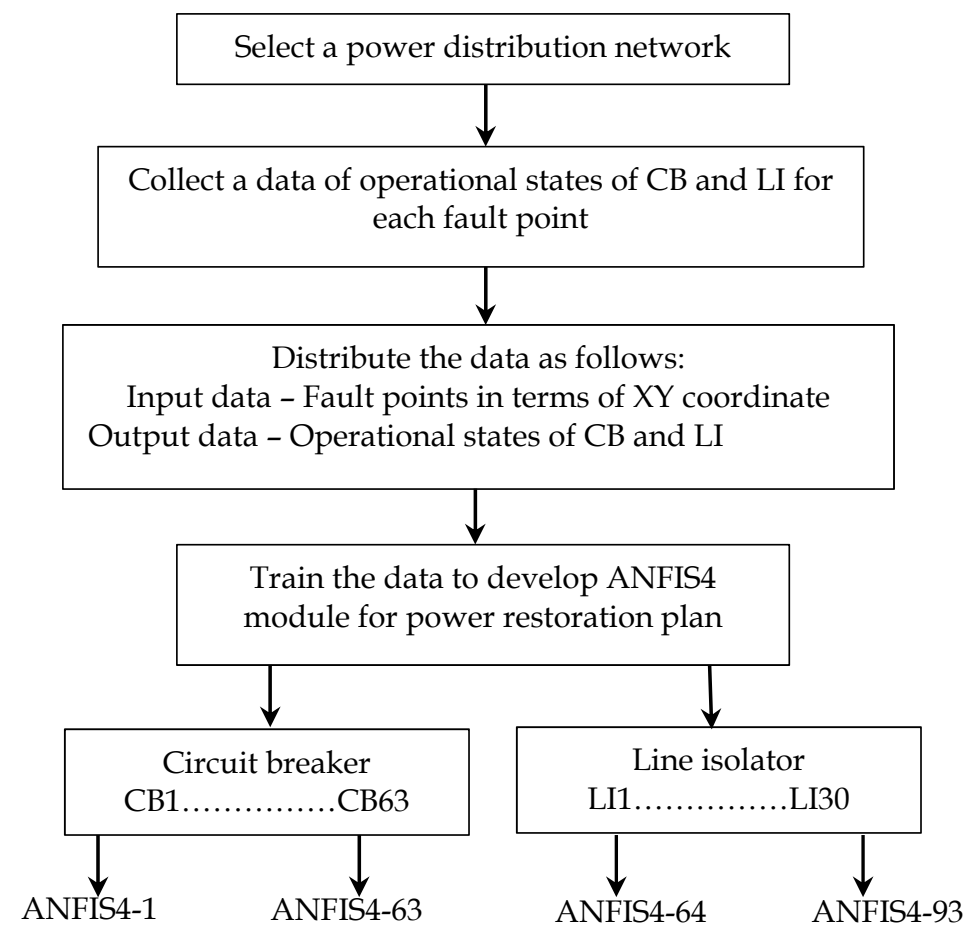

Fig. 16. A procedure for developing ANFSI4 module in power restoration plan

\begin{tabular}{|c|c|c|c|c|}
\hline ANFIS1 module & $\begin{array}{c}\text { Generated } \\
\text { data set }\end{array}$ & $\begin{array}{c}\text { Trained } \\
\text { data set }\end{array}$ & $\begin{array}{c}\text { Number of } \\
\text { ANFIS } \\
\text { input }\end{array}$ & $\begin{array}{c}\text { Number of } \\
\text { ANFIS } \\
\text { output }\end{array}$ \\
\hline ANFIS4-1 & 80 & 59 & 2 & 1 \\
\hline & $"$ & $"$ & 2 & 1 \\
\hline$\downarrow$ & " & $"$ & 2 & 1 \\
\hline ANFIS4-93 & " & " & 2 & 1 \\
\hline
\end{tabular}

Table 5. A distribution of the data set for power restoration plan 


\section{The result of fault diagnosis}

Fault diagnosis performance is measured through a precision and accuracy of ANFIS prediction. The measurement is in percentage error for ANFIS1, ANFIS2 and ANFIS3 while in absolute error for ANFIS4. The 47 buses practical system is used to test the ANFISs. The prediction results from ANFIS1, ANFIS2 and ANFIS3 are presented for practical systems that consist of 1232 test data sets. Meanwhile, ANFIS4 predicts about 2743 test data sets for the same system. The number of test data set is taken from $50 \%$ of overall data training.

\subsection{The result on ANFIS1 prediction for classifying types of fault}

Fig.17 shows the curve of a percentage error and a real target value for ANFIS1 prediction in classifying fault types in 47 buses practical system. The average percentage error for such power systems is $2 \mathrm{E}-5 \%$. Meanwhile, the maximum percentage error for the same power system is $0.52 \%$. From the result on ANFIS1 in classifying the types of fault in terms of integer 1 to 10, it can be said that the ANFIS module is able to show precise prediction.

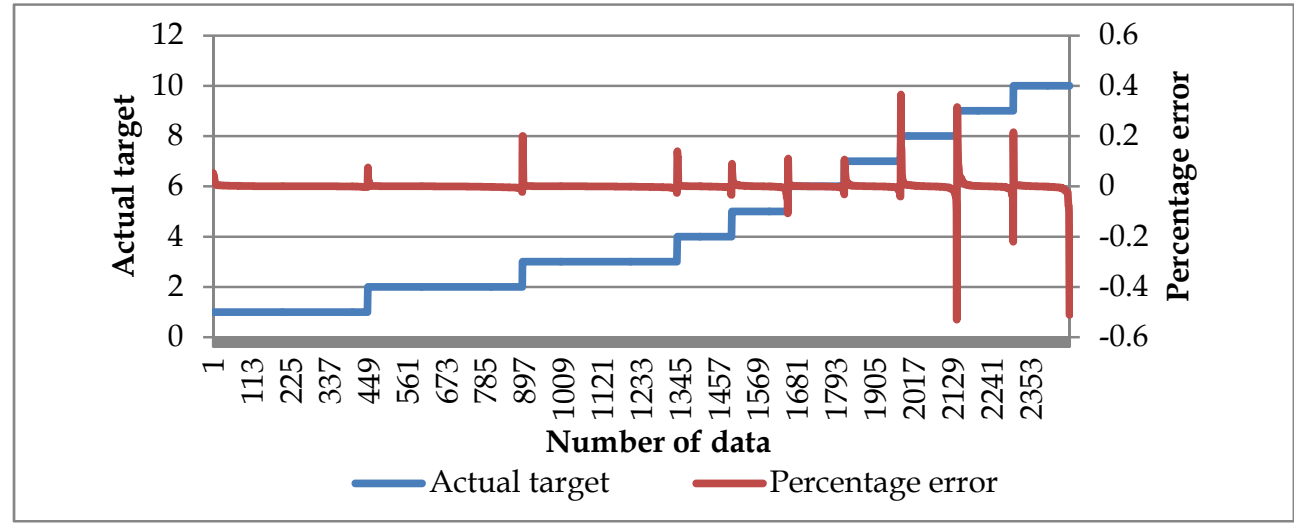

Fig. 17. The result on ANFIS1 prediction for classifying types of fault in the 47 buses practical system.

\subsection{The result of ANFIS2 for identifying fault location in terms of $X$ coordinate}

The average percentage error of $1.2 \mathrm{E}-5 \%$ is the result of ANFIS2 prediction for identifying the fault location in terms of $\mathrm{X}$ coordinate as shown in Fig.18. From the figure, the maximum percentage error is $1.8 \%$ in the 47 buses practical system. As a conclusion based on the result, it can be seen that the developed ANFIS2 module is more precise in predicting the fault location than the developed ANN (artificial neural network) module with the same data. 


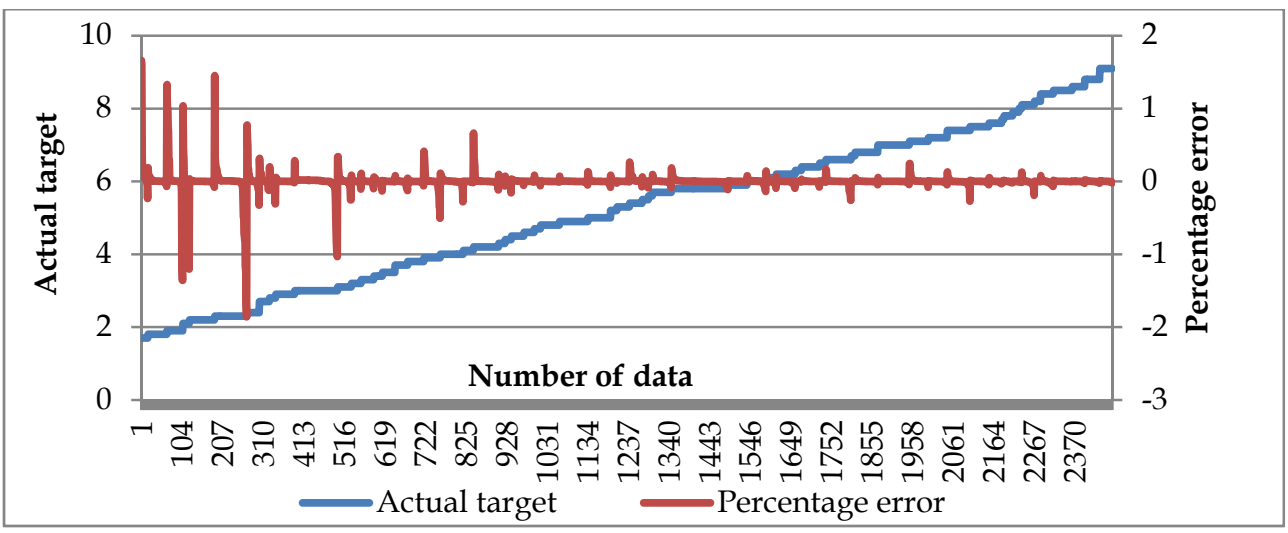

Fig. 18. The result of ANFIS2 prediction for identifying fault location in terms of $X$ coordinate in the 47 buses practical system.

\subsection{The result of ANFIS3 for identifying fault location in terms of $Y$ coordinate}

Fig.19 shows the result of ANFIS3 for identifying the fault location in terms of $Y$ coordinate in the 47 buses practical system. It is found that about $2.1 \mathrm{E}-2 \%$ is the average percentage error and $10.7 \%$ is the maximum percentage error of the ANFIS3 prediction. As a conclusion, ANFIS3 has a high precision for identifying the fault location in terms of $Y$ coordinate based on the average percentage error for 2464 numbers of data training in the system.

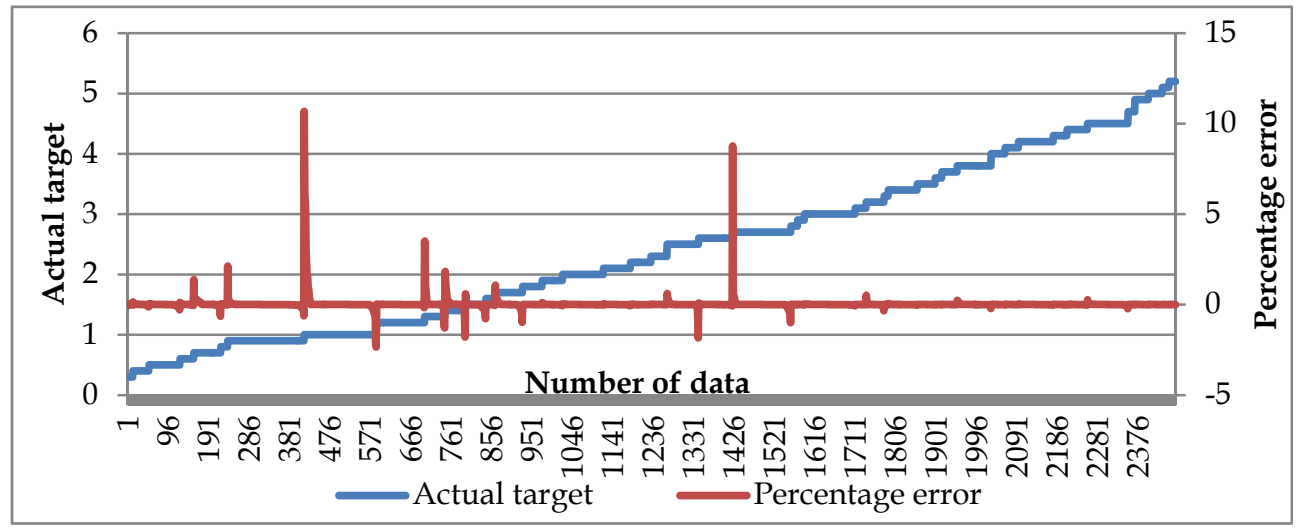

Fig. 19. The result on ANFIS2 prediction for identifying fault location in terms of $Y$ coordinate in the 47 buses practical system.

\subsection{The result on ANFIS4 for planning power restoration}

Fig.20 shows the result on ANFIS4 prediction in determining the operational states of CB and LI for power restoration plan. Both devices are provided in the 47 buses practical system as a test network for the task. The result shows that the average absolute and maximum absolute errors are 1.14E-7 and 0.028 respectively. Referring to the Fig.20, B1 up 
to B26 represent 26 buses in the $11 \mathrm{KV}$ of practical system. According to the result, ANFIS4 module gives a high accuracy in the prediction of the operational states of CB and LI for power restoration plan.

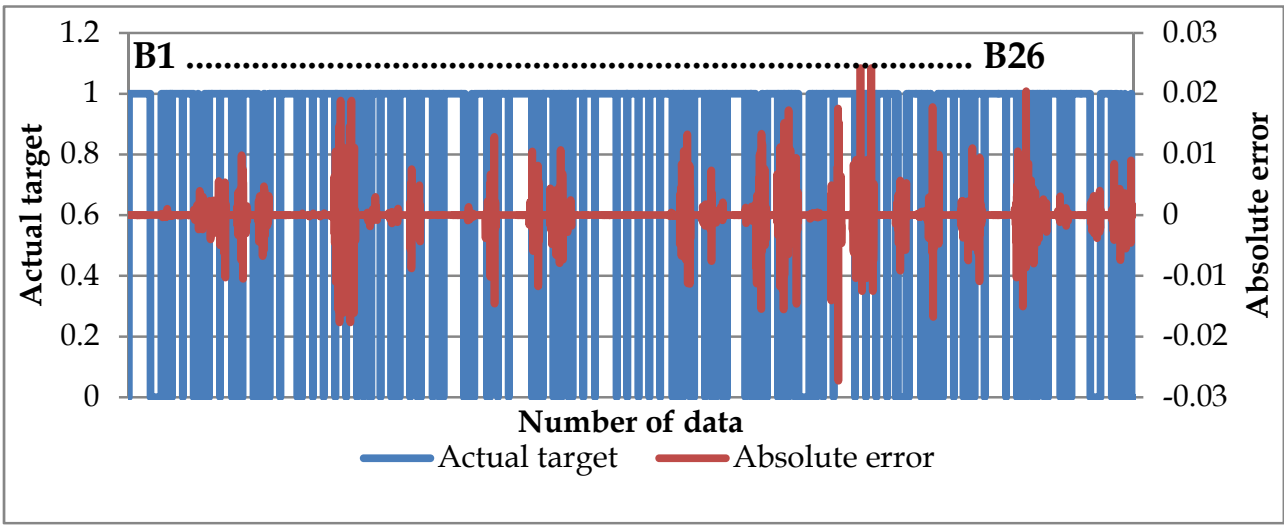

Fig. 20. The result on ANFIS4 prediction for determining operational states of CB and LI for power restoration plan in 47 buses practical system.

\section{Conclusion}

In general, this chapter describes an accurate method for identifying various fault types as well as the location for the purpose of power restoration plan using the operational states of $\mathrm{CB}$ and LI in the power distribution system. For this purpose, the ANFIS approach has been developed by using the representative integers 1 to 10 in classifying ten types of fault. This adaptive approach is also implemented to identify the fault location in power distribution system in terms of geometrical coordinates. Since the developed ANFIS modules are a useful fault diagnosis tool in completing the task, this approach is continuously developed for power restoration plan through network reconfiguration by controlling the operational states of $\mathrm{CB}$ and LI. The performance of ANFIS is tested on a 47 buses practical system in which it shows more precision when predicting the target for the developed fault diagnosis system.

\section{Acknowledgment}

This work of research has been financially supported by the Univerti Kebangsaan Malaysia (UKM) and the Universiti Teknologi Malaysia (UTM).

\section{References}

Binh, P.T.T., \& Tuyen, N.D. (2006). Fault Diagnosis of Power System Using Neural Petri Net and Fuzzy Neural Petri Nets, Power India Conference, IEEE, pp. 5, ISBN 0-7803-95255, New Delhi, India, n.d.

Butler-Purry, K.L. \& Marotti, M. (2006). Impact of Distributed Generators on Protective Devices in Radial Distribution Systems, Proceedings of the IEEE Power Engineering Society in Transmission and Distribution Conference, pp. 87-88, ISBN 0-7803-9194-2, Dallas, Texas, USA, May 21-24, 2006 
Fauziah, A. (January 2005). PM Mahu Laporan Segera - TNB Diarah Siasat Terperinci Punca Gangguan Bekalan Elektrik, In: Utusan Malaysia, 14.01.2005, Available from http://www.utusan.com.my/utusan/info.asp?pub=Utusan_Malaysia\&sec=Berita _Utama

Jang, J.-S.R. (1993). ANFIS: Adaptive Network Based Fuzzy Inference System. IEEE Transaction on Systems, Man and Cybernetic, Vol.23, No.3, pp. 665-685, ISSN 0018-9472

Marusic, A. \& Gruhonjic-Ferhatbegovic, S. (2006). A Computerized Fault Location Process for Overhead Radial Distribution Feeders, IEEE Mediterranean Conference on Electrotechnical, pp. 1114-1117, ISBN 1-4244-0087-2, Benalmadena, Malaga, Costa del Sol, May 16-19, 2006

Michael Negnevitsky. (2005). Artificil Intelligent: A Guide to Intelligent System, AddisonWesley, ISBN 0-321-20466-2, Harlow, England

Mitra, P., Maulik, S., Chowdhury, S.P. \& Chowdhury, S. (2008). ANFIS Based Automatic Voltage Regulator with Hybrid Learning Algorithm. International Journal of Innovations in Energy Systems and Power, Vol. 3, No.2, pp. 1-5, ISSN 1913-135X

Mohamed, A. \& Mazumder. (1999). A Neural Network Approach to Fault Diagnosis in a Distribution System. International Journal of Power and Energy systems. Vol.19, No.2, pp. 129-134, ISSN 1078-3466

Oliveira, K.R.C. (2007). Advanced Intelligent Computing Theories and Applications with Aspects of Artificial Intelligent, Springer Berlin, ISBN 978-3-540-74201-2

Richard, E.B.( 2009). Electric Power Distribution Reliability. CRS Press, ISBN 978-0-8493-7567-5, USA

Sadeh, J. \& Afradi, H. (2009). A New and Accurate Fault Location Algorithm for Combined Transmission Lines Using Adaptive Network-Based Fuzzy Inference System. Journal of Electric Power System Research, Vol.79, No.11, pp. 1538-1545, ISSN 0378-7796

Sekine, Y., Akimonto, Y., Kunugi, M. \& Fukui, C. (1992). Fault Diagnosis of Power System. Proceedings of the IEEE. Vol.80, No.5, pp. 673-683, ISSN 0018-9219

Silva, K.M., Souza, B.A. \& Brito, N.S.D. (2006). Fault Detection and Classification in Transmission Lines Based On Wavelet Transform and ANN. IEEE Transaction on Power Delivery, Vol.21, No.4, pp. 2058-2063, ISSN 0885-8977

Souza, J.C.S., Meza, E.M., Sebilling, M.T. \& Do Corato, M.B. (2004). Alarm Processing in Electrical Power Systems through a Neuro-Fuzzy Approach. IEEE Transaction on Power Delivery, Vol.19, No.2, pp. 537-544, ISSN 0885-8977

Thomas Tamo Tatiesa \& Joseph Voufo. (2009). Fault Diagnosis on Medium Voltage (MV) Electric Power Distribution Networks: The Case of The Downstream Network of The AES-SONEL Ngousso Sub-Station. Journal of Energies, Vol.2, No.2, pp. 243-257, ISSN 1996-1073

Zhisheng Zhang \& Yarning Sun, 2007. Assessment on Fault-Tolerance Performance Using Neural Network Model Based on Ant Colony Optimization Algorithm for Fault Diagnosis in Distribution Systems of Electric Power Systems, The $8^{\text {th }}$ International Conference on Software Engineering, Artificial Intelligent, Networking and Parallel Distributed Computing, pp. 712-716, ISBN 0-7695-2909-7, Qingdao, China, July 30 August 1, 2007

Zhiwei Liao, Fushuan Wen, Wenxin Guo, Xiangzhen He, Wei Jiang, Taifu Dong, Junhui \& Binghua Xu. (2008). An Analytic Model and Optimization Technique Based Methods for Fault Diagnosis in Power System. The 3rd International Conference on Electric Utility Deregulation and Restructuring and Power Technologies, pp. 1388-1393, ISBN 978-7-900714-13-8, Nanjuing, China, April 6-9, 2008 


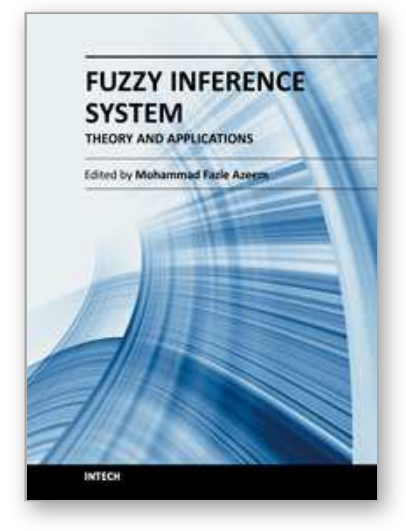

\author{
Fuzzy Inference System - Theory and Applications \\ Edited by Dr. Mohammad Fazle Azeem
}

ISBN 978-953-51-0525-1

Hard cover, 504 pages

Publisher InTech

Published online 09, May, 2012

Published in print edition May, 2012

This book is an attempt to accumulate the researches on diverse inter disciplinary field of engineering and management using Fuzzy Inference System (FIS). The book is organized in seven sections with twenty two chapters, covering a wide range of applications. Section I, caters theoretical aspects of FIS in chapter one. Section II, dealing with FIS applications to management related problems and consisting three chapters. Section III, accumulates six chapters to commemorate FIS application to mechanical and industrial engineering problems. Section IV, elaborates FIS application to image processing and cognition problems encompassing four chapters. Section V, describes FIS application to various power system engineering problem in three chapters. Section VI highlights the FIS application to system modeling and control problems and constitutes three chapters. Section VII accommodates two chapters and presents FIS application to civil engineering problem.

\title{
How to reference
}

In order to correctly reference this scholarly work, feel free to copy and paste the following:

Rasli, Hussain and Fauzi (2012). Fault Diagnosis in Power Distribution Network Using Adaptive Neuro-Fuzzy Inference System (ANFIS), Fuzzy Inference System - Theory and Applications, Dr. Mohammad Fazle Azeem (Ed.), ISBN: 978-953-51-0525-1, InTech, Available from: http://www.intechopen.com/books/fuzzy-inferencesystem-theory-and-applications/fault-diagnosis-in-power-distribution-network-using-adaptive-neuro-fuzzyinference-system-anfis

\section{INTECH}

open science | open minds

\section{InTech Europe}

University Campus STeP Ri

Slavka Krautzeka 83/A

51000 Rijeka, Croatia

Phone: +385 (51) 770447

Fax: +385 (51) 686166

www.intechopen.com

\section{InTech China}

Unit 405, Office Block, Hotel Equatorial Shanghai

No.65, Yan An Road (West), Shanghai, 200040, China

中国上海市延安西路65号上海国际贵都大饭店办公楼 405 单元

Phone: +86-21-62489820

Fax: $+86-21-62489821$ 
(C) 2012 The Author(s). Licensee IntechOpen. This is an open access article distributed under the terms of the Creative Commons Attribution 3.0 License, which permits unrestricted use, distribution, and reproduction in any medium, provided the original work is properly cited. 